\title{
Performance of multistage filtration using different filter media against conventional water treatment systems
}

\author{
GMM Ochieng ${ }^{1}$, FAO Otieno ${ }^{1 *}$, TPM Ogada $^{2}$, SM Shitote ${ }^{2}$ and DM Menzwa ${ }^{2}$ \\ ${ }^{1}$ Faculty of Engineering, Tshwane University of Technology, Private Bag X680, Pretoria 0001, South Africa \\ ${ }^{2}$ Faculty of Technology, Moi University, PO Box 3900 Eldoret 30100, Kenya
}

\begin{abstract}
This study was aimed at introducing multistage filtration (MSF) (a combination of slow-sand filtration (SSF) and pretreatment system - horizontal flow roughing filter (HRF)) as an alternative water treatment technology to the conventional one. A pilot- plant study was undertaken to achieve this goal. Evaluating the MSF performance vs. the existing conventional system in removing selected physical and chemical drinking water quality parameters together with the biological water quality improvement by the MSF without chemical use was done. Evaluation of the effectiveness of the MSF system utilizing locally available material, i.e. gravel, improved agricultural waste (charcoal maize cobs) and broken burnt bricks as pretreatment filter material was also done The benchmark was the Kenya Bureau of Standards (KEBS) values for the selected parameters. Results showed that with proper design specifications, MSF systems perform better than conventional systems under similar conditions of raw water quality and environmental conditions. The tested locally available materials can also be effectively used as pretreatment media with each allowing a filter run greater than $82 \mathrm{~d}$ and therefore could serve as alternatives where natural gravel is not readily available. With special reference to the bacteriological quality improvement, the MSF greatly improved the bacteriological quality of the water recording removal efficiencies of over $99 \%$ and $98 \%$ respectively for $E$. coli and total coliforms. Despite the observed performance, MSF should be complemented with chlorination as a final buffer against water-borne diseases. However, in this case, the dosing will be greatly reduced when compared to the conventional system.
\end{abstract}

Keywords: multistage filtration, gravel, charcoal maize cobs, broken burnt bricks, pretreatment, conventional

\section{Nomenclature}

HRF: Horizontal flow roughing filter

HRFB: HRF with broken burnt bricks as filter medium

HRFC: HRF with charcoal maize cobs as filter medium

HRFG: HRF with gravel as filter medium

SSF: Slow-sand filter/filtration

SSFB: SSF connected to HRFB

SSFC: SSF connected to HRFC

SSFG: SSF connected to HRFG

MSF: Multistage filter/filtration

MSFB: MSF combining HRFB with SSFB

MSFC: MSF combining HRFC with SSFC

MSFG: MSF combining HRFG with SSFG

RSF: Conventional treatment system

CFU: Colony-forming units

SS: $\quad$ Suspended solids concentration

NTU: Nephelometric turbidity units

\section{Introduction}

Over $80 \%$ of the water used in both rural and urban areas in Kenya is surface water drawn from rivers, streams, lakes, ponds and springs. The water from these sources is in most cases contaminated by human and animal wastes, as well as industrial and agricultural activities. This scenario thus calls for efficient and effective treatment of water from such sources before use to avoid

* To whom all correspondence should be addressed.

政+2712 318-5120; fax: +2712 318-5568; e-mail: otienofao@tut.ac.za Received 22 August 2003; accepted in revised form 12 March 2004. instances of water-borne and water- related diseases such as typhoid fever and cholera at reasonable costs. This is important because it has been reported that 70 to $80 \%$ of water-borne diseases are spread through the unavoidable ingestion of pathogenic microorganisms and parasites in drinking untreated water especially surface water (Tebbutt, 1992). It has also been shown that inadequate water supply both in terms of quantity and quality coupled with poor sanitation globally account for approximately 30000 deaths daily, many of them infants and $80 \%$ of such cases occur in rural areas (WHO and UNICEF, 1996). A WHO report during the celebration of world water day on 22 March 2001 (theme "Water for Health") showed that in Kenya, only $49 \%$ of the total population has access to safe water according to UNICEF statistics.

In providing water on a large scale, slow-sand filtration and conventional treatment methods (of coagulation - flocculation sedimentation - rapid filtration - chlorination) are mostly used, the Kenyan practice, like in most other countries, being to adopt the conventional water treatment method. This system is, however, quite demanding in chemical use, energy input and mechanical parts as well as skilled manpower that are often unavailable, especially in rural areas of developing countries. This scenario calls for appropriate technologies that utilise locally available materials, skills and other resources in accessing potable water. One such technology is MSF (Wegelin, 1996). This system consists of a pretreatment stage followed by SSF. Worldwide experience with roughing filters and SSFs shows the significant potential of this treatment concept in producing potable drinking water from polluted turbid water (Wegelin, 1996). Application of MSF in Europe has, according to Wegelin et al. (1990), shown tremendous success in Dortmund, Germany (Waterworks of Dortmund), Austria (Graz Water Supply Authority) and Aesh in Switzerland among others. In 
developing countries such as in Asia, Africa and Latin America, installation and operation of MSFs have shown great applicability of the system for a sustainable water supply. These include Sudan Geriza Irrigation Scheme (Blue Nile Health Project), Guder's treatment plant in Ethiopia, Columbia and India as examples. Several studies have also shown that MSF is a simple, efficient and cheap water treatment technology compared to the conventional system (e.g. Deshpande et al., 1997; Galvis et al., 1993). This is in terms of technical labour requirement, daily operation and maintenance costs and treatment efficiency and effectiveness. However, cost analysis shows that initial installation cost of MSF is higher than that of a conventional system (Wegelin et al., 1986). This stems from the fact that the low filtration rates of 0.5 to $1.0 \mathrm{~m} / \mathrm{h}$ for $\mathrm{HRF}$ and 0.1 to $0.3 \mathrm{~m} / \mathrm{h}$ for SSF demand larger land areas that might not be available in densely populated urban areas. SSFs also contain from 50 to 100 times more volume of graded-sand than rapid- sand filters and the supply and cost of this material will be a problem where sand is not available locally (Pescod et al., 1990). However, these disadvantages of high initial costs are outweighed by the low cost of operation and maintenance (Wegelin, 1986).

\section{Objectives of the study}

The general objective of this work was to evaluate the performance of MSFs vs. the conventional system in removing selected parameters guiding drinking water quality while operating under similar conditions of raw water quality (same source) and environmental conditions. The specific objective was to evaluate the effectiveness of the MSF system utilising locally available material as pretreatment media.

\section{Experimental work}

To undertake the study objectives described above, a pilot plant was built at Moi University main campus (Waterworks). Moi University Waterworks is a conventional water treatment plant. The location of the pilot plant at the Waterworks was for convenience and logistic reasons. The plant could, however, have been sited anywhere else.

In this study, HRFs were selected as the pretreatment filters followed by SSFs as the final filters. There was no disinfection of the filtrate. The choice of HRFs as the pretreatment filters was based on previous research findings that for tropical regions, HRFs perform better than other pretreatment systems (Boller, 1993). HRFs also have advantages of simplicity in design, cleaning, and operation and in their ability to handle higher turbidity ranges of between 50 and 200 NTU with short turbidity peaks of 500 to 1000 NTU. This is a safe range in the tropics where turbidities as high as 5000 NTU can occur (Boller, 1993). Slow-sand filters on the other hand have shown unrivalled ability to improve biological water quality with over $90 \%$ efficiency in micro-organism reduction. They are also simple to design, operate and maintain (Wegelin, 1996). Three locally available materials were tested for suitability as HRF material. These were gravel, broken burnt bricks, and improved agricultural waste (charcoal maize cob). The HRF filter medium was composed of relatively coarse material ranging from $5 \mathrm{~mm}$ to $15 \mathrm{~mm}$ in size. The three HRF materials were tested simultaneously using the same raw water. Each HRF unit then had its own SSF to feed. The SSFs were filled with river sand of effective size $0.25 \mathrm{~mm}$ and uniformity coefficient of 2.4 . The parameters investigated were turbidity, SS, E. coli and, total coli. The selection of these test parameters was based on the KEBS recommendations (KEBS, 1996) on basic parameters that define drinking water quality and also on recommendations of Galvis et al. (1993) on the key parameters that are useful in the study of the performance of an MSF system. Monitoring of head loss development in SSFs as an indicator of filter run length was also done. The pilot plant was checked daily to correct for any possible external interference that resulted from curious on- lookers and visitors to the Waterworks who would at times interfere with the set filtration rates. This had to be corrected for immediately so as to obtain credible results.

\section{Pilot-plant unit}

\section{Horizontal flow roughing filters (HRF)}

The design and sizing of the pilot-plant HRFs were guided by the Wegelin design criteria (Wegelin, 1986) based on the preliminary raw water quality data obtained prior to the commencement of the full pilot-plant study. The filter was divided into three parts:

- The inlet structure.

- The outlet structure.

- The filter bed.

The inlet and outlet structures were flow-control installations required to maintain a certain water level and flow along the filter as well as to establish an even flow distribution along and across the filter. The filter bed was composed of three filter medium packs of different sizes. The filter medium was placed in separate compartments starting with the coarsest to the finest, in the direction of flow and operated in series. The first compartment was filled with filter material of effective size $15 \mathrm{~mm}$ followed by $10 \mathrm{~mm}$ in the second compartment and $5 \mathrm{~mm}$ in the last compartment. Perforated wall segments to avoid mixing during cleaning separated each fraction. The filter bed was provided with under-drain systems to enable hydraulic sludge extraction to be carried out after a certain running period. Figure 1 shows the pilot-plant scale HRF unit used.

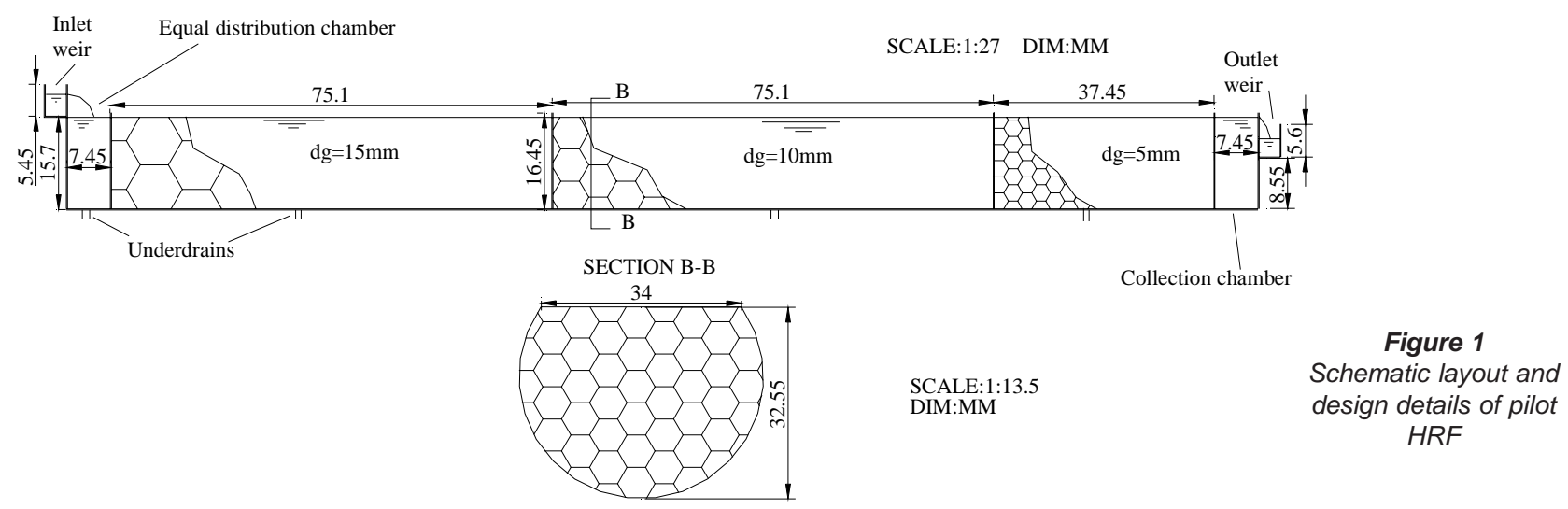




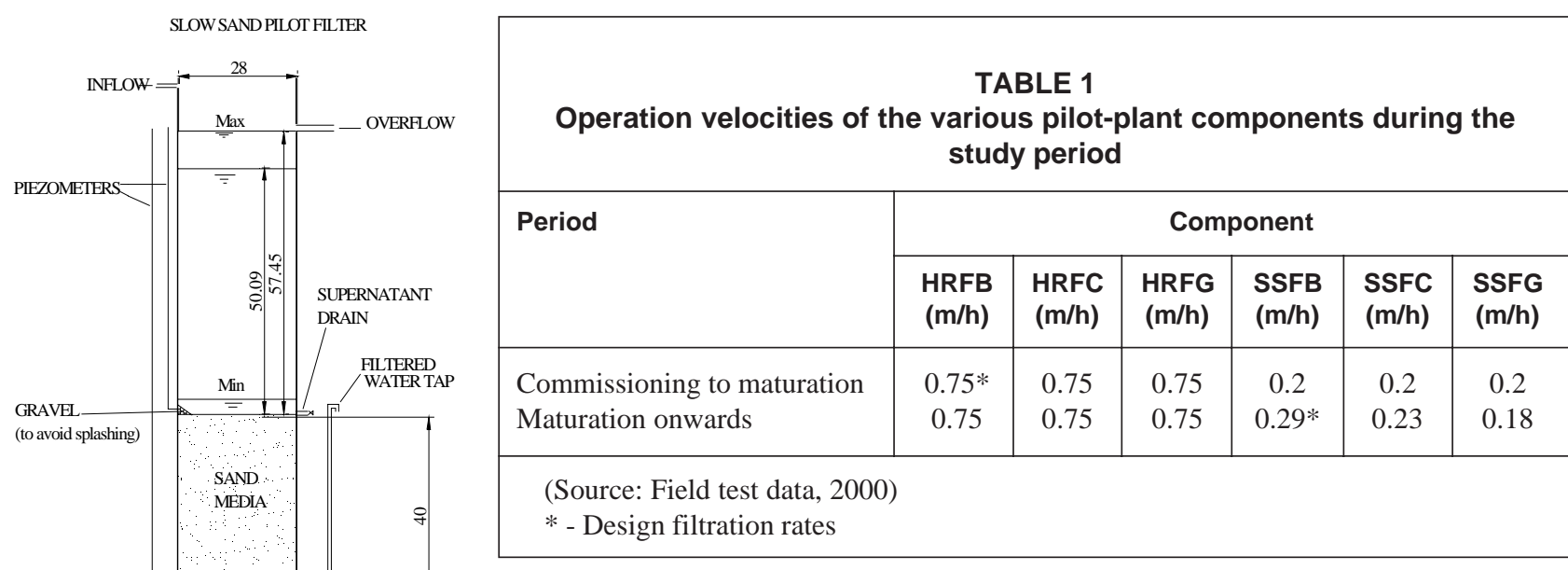

\section{Pilot-plant operation}

Table 1 shows the operation velocities of the plant during the study period.

The staggering of the filtration rates was deliberate, in an attempt to check the filters' sensitivity to filtration rates in terms of the head loss development and overall performance.

\section{Data analysis}

Laboratory tests, secondary data and field recordings were used to analyse and interpret data for both MSF and RSF units. Percentage removal of the units for the selected drinking water quality parameters was obtained as a measure of performance. Comparison of the final MSFs' effluent and conventional treatment system effluent quality was done. The KEBS standards were also used to check the final MSFs' effluent vs. the conventional treatment system effluent for meeting the drinking water standards as set. Analysis was done considering dry and rainy season periods. Resistance development in the various SSF units was also monitored in the field. This was to aid the assessment of the filter run period (time between two successive cleaning cycles) for the SSFs under the set operating conditions.

A bed of fine sand (filter medium) that achieves the filtration and other effects.

- A system of under-drains to allow unobstructed passage of treated water and to support the filter medium so that a uniform filtration rate is maintained over the whole area of the filter.

- Filter regulation and control devices.

- An inlet and outlet structure.

- A filter box to house the filter medium, supernatant water and under-drains.

\section{General pilot-plant layout (schematic)}

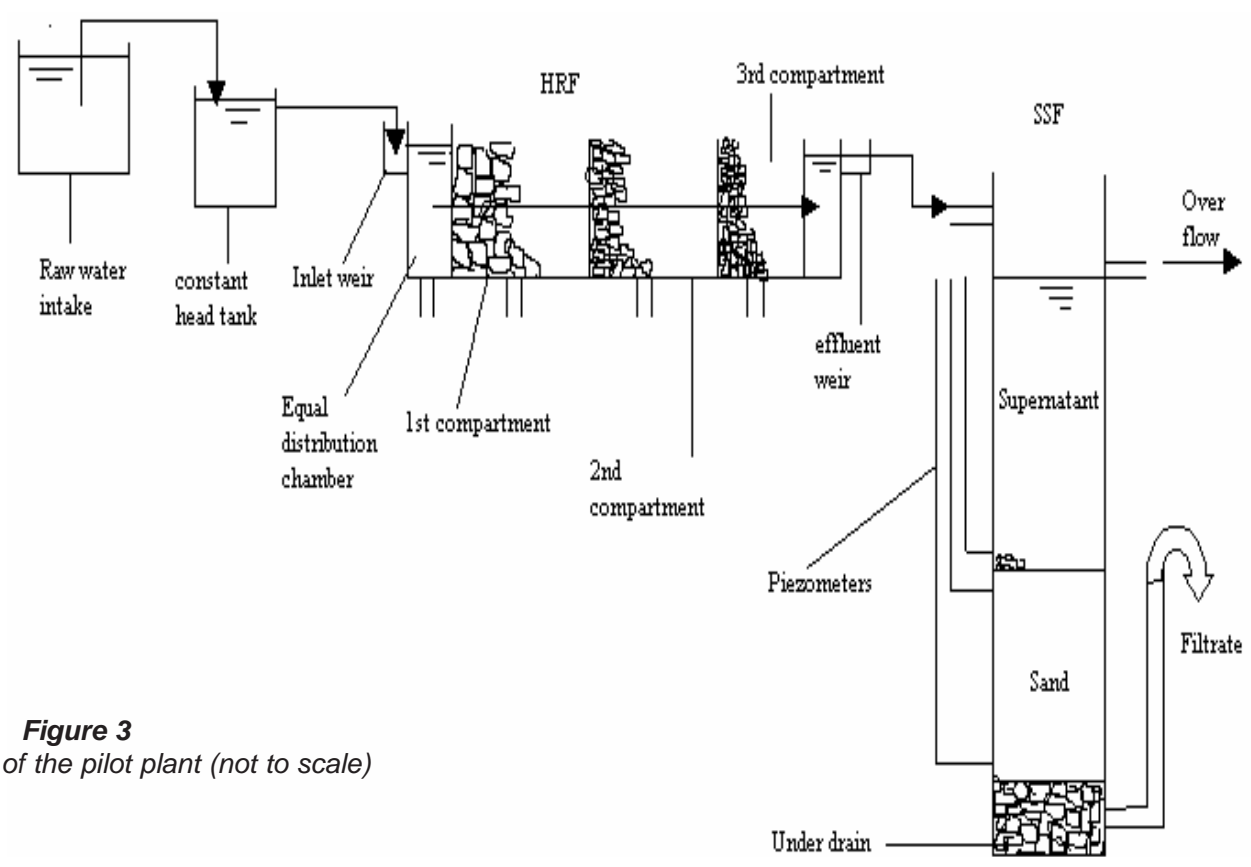




\begin{tabular}{|l|c|c|c|c|}
\hline \multicolumn{4}{|c|}{ TABLE 2 } \\
\hline Period & $\begin{array}{c}\text { SS } \\
\text { (mg/ } \ell \text { ) }\end{array}$ & $\begin{array}{c}\text { Turbidity } \\
\text { (NTU) }\end{array}$ & \multicolumn{2}{|c|}{$\begin{array}{c}\text { Bacteria } \\
\text { (CFU/100 m } \ell)\end{array}$} \\
\cline { 3 - 5 } & & & E. coli & Total coli \\
\hline Low peak & $9.2-31.7$ & $12.4-29.62$ & $32-72$ & $94-324$ \\
High peak & $30.1-116$ & $30.65-123.8$ & $52-110$ & $108-420$ \\
\hline (Source: Field test data, 2000) & \\
\hline
\end{tabular}

\begin{tabular}{|c|c|c|c|c|c|c|c|c|}
\hline \multicolumn{9}{|c|}{$\begin{array}{c}\text { TABLE } 3 \\
\begin{array}{c}\text { Average overall per cent removal of SS and turbidity for } \\
\text { the MSFs vS. RSF }\end{array}\end{array}$} \\
\hline \multirow[t]{2}{*}{ Period } & \multicolumn{4}{|c|}{$\begin{array}{l}\text { Average SS } \\
\text { removal (\%) }\end{array}$} & \multicolumn{4}{|c|}{$\begin{array}{l}\text { Average turbidity } \\
\text { removal (\%) }\end{array}$} \\
\hline & MSFB & MSFC & MSFG & RSF & MSFB & MSFC & MSFG & RSF \\
\hline Low peak & 93 & 93 & 92 & 88 & 92 & 92 & 93 & 91 \\
\hline High peak & 98 & 98 & 98 & 96 & 98 & 98 & 98 & 97 \\
\hline Average & 95 & 95 & 94 & 91 & 94 & 94 & 95 & 93 \\
\hline
\end{tabular}

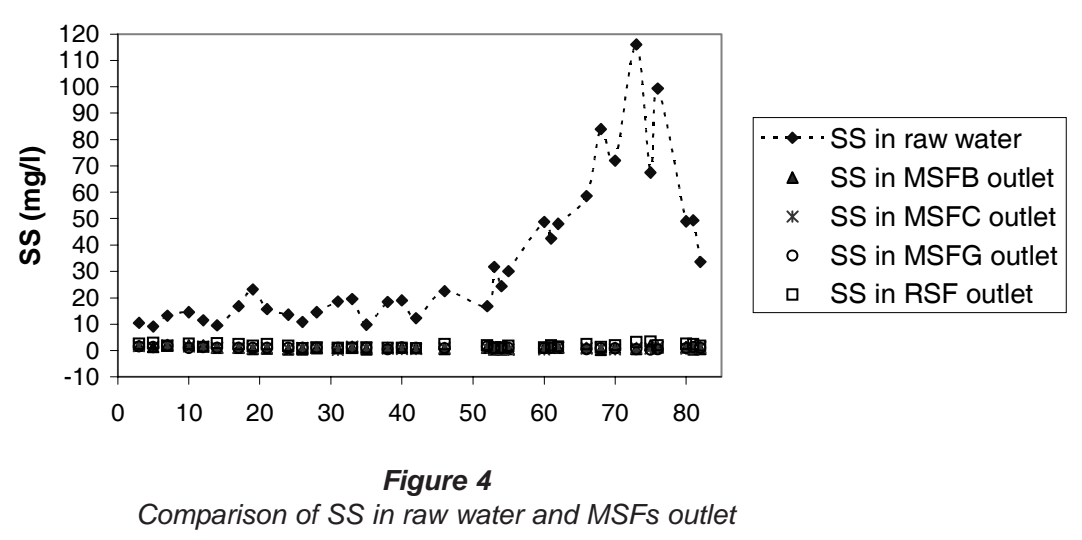

\section{Results and discussions}

\section{Quality of raw water}

Table 2 shows a summary of the range of raw water quality parameters during the study period.

From Table 2, it can be observed that great variations in raw water quality parameters were experienced in both low peak (dry season) and high peak (rainy season) periods. Thus, several peaks and troughs were expected in the performance trends going by the recorded ranges. The lower levels in SS and turbidity in the dry season, for instance compared to the rainy season, were attributed to the effect of runoff from fields during the rainy season causing an increase in sediment and other impurity loads in the raw water as opposed to the dry season where the major contribution to streamflow is from baseflow and therefore fairly clear water is experienced. The source water is used for various purposes such as animal watering, irrigation and other domestic purposes. These activities have an effect on the quality of water, hence the daily variations in the observed trends (see Figs. 4, 5, 8 and 9). It is also worth noting the recorded relationship between SS concentration and turbidity levels in both periods. This could be attributed to the fact that the clarity of water (measured by turbidity) is a direct function of the concentration of SS (especially those in colloidal state) in the water.

\section{Overall performance of MSFs vs. conventional system}

Evaluation of overall performance of MSF units vs. the conventional treatment system of coagulation - flocculation - sedimentation - rapidsand filtration herein referred to as RSF was done by comparing the final filtrates from both systems with the raw water conditions. According to KEBS, SS, turbidity and coliform concentrations in water are key parameters in determining potable water quality. According to recommendations of Galvis et al. (1993), these parameters are also key in the study of performance of a MSF system. Hence for this evaluation, the parameters considered were turbidity, SS and coliform concentrations. The samples tested were collected simultaneously from both systems for comparative studies.

\section{Removal of SS and turbidity}

Average per cent removals in both systems are as given in Table 3. The trends observed are as shown in Figs. 4 and 5. As depicted in Figs. 4 and 5, all the systems were consistent in the removal trends for both SS and turbidity with both systems recording values close to zero in most cases. Table 3 shows that generally all MSF units performed better than the conventional system (RSF) in removal of SS and turbidity even though by a small but recognisable per cent margin. Figures 6 and 7 show the average performance (based on Table 3) of MSFs vs. RSF with respect to SS and turbidity removal.

Figure 5

Comparison of Turbidity levels in raw water and MSFs outlet 


\section{Bacteriological quality improvement (MSF)}

Bacteriological quality of the end water passing through a treatment system is of utmost concern in terms of efficiency of either system in producing water suitable for domestic consumption. In this regard, consideration was given to evaluating the performance of MSFs in improving bacteriological water quality given that this is one of its strongest attributes when compared to other treatment systems. Average per cent removals in both seasons were considered as given in Table 4. Figures 8 and 9 show the removal trends observed for the MSFs in regard to bacteriological quality improvement.

On average, it was found that MSFs performed considerably well in removing E. coli and total coli as depicted in Table 4 and also observed in Figs. 8 and 9. Observations from Figs 8 and 9 show that at the start of each filter run, the removal efficiencies were low in comparison to the subsequent periods. This can be attributed to the fact that during this period, the filter was establishing itself in terms of the full development and establishment of the filter skin Schmutzdecke. This observation could be linked to the filtration rates and mode of action in this system. MSF removal processes are mainly physical and biological. Coupled with the low filtration rates in the SSFs, this allows for longer detention time of water within the filter bed and also assists in the development of the Schmutzdecke, which plays an important role in SSF straining and biological activity.

\section{Comparison of final effluent quality parameter levels (selected) with the KEBS set values}

The main purpose of any water treatment process is to improve the water quality in terms of its biological, chemical and physical constituents to fit the intended end-use quality. The quality of drinking water that is the intended end-use in this study is thus described by its physical, chemical, and biological characteristics. In comparing the final effluent condition of both MSF and the

\begin{tabular}{|c|c|c|c|c|c|c|}
\hline \multicolumn{7}{|c|}{$\begin{array}{c}\text { TABLE } 4 \\
\begin{array}{c}\text { Average overall per cent removal of bacteria } \\
\text { for MSFs }\end{array}\end{array}$} \\
\hline \multirow[t]{2}{*}{ Period } & \multicolumn{3}{|c|}{$\begin{array}{l}\text { Average } E \text {. coli } \\
\text { removal (\%) }\end{array}$} & \multicolumn{3}{|c|}{$\begin{array}{l}\text { Average total coli } \\
\text { removal (\%) }\end{array}$} \\
\hline & MSFB & MSFC & MSFG & MSFB & MSFC & MSFG \\
\hline Low peak & 87 & 86 & 88 & 86 & 86 & 82 \\
\hline High peak & 99.5 & 99 & 99.6 & 98.1 & 98.4 & 98.8 \\
\hline Average & 90.7 & 90.3 & 91.4 & 90.1 & 89.9 & 87.1 \\
\hline \multicolumn{7}{|c|}{ (Source: Field test data: 2000) } \\
\hline
\end{tabular}

conventional rapid filter treatment process, the intention was to show that MSF, through combining only simple physical and biological purification processes, can perform better than the conventional system. In reference to the MSFs, the values used in comparison were those obtained after the SSFs maturation. This was done to compare the MSFs' performance with the existing conventional system at a time when MSFs are at their best performance. It is also worth noting that the conventional treatment final effluent samples were obtained before chlorination. Table 5 presents the average and respective ranges of the effluents' selected quality parameter levels vs. the KEBS drinking water standards.

In general, none of the systems conclusively met the set KEBS drinking water standards. From the results, disinfection was necessary for all the MSFs and conventional system's effluents. Therefore, turbidity of less than 1 NTU was required. The worst MSF effluent was off the standard by $4 \%$ compared to $50 \%$ for conventional systems in this regard. For SS concentrations, nil concentration is the standard. In this regard, the worst MSF effluent was 0.91 $\mathrm{mg} / \ell$ compared to $1.76 \mathrm{mg} / \ell$ for conventional systems. For coliform concentrations, the standard is zero CFU/100m $\ell$. MSFs
Figure 6

Comparison of the overall performance of MSFs vs RSF in SS removal
Figure 7

Comparison of the overall performance of MSFs vs RSF in Turbidity removal
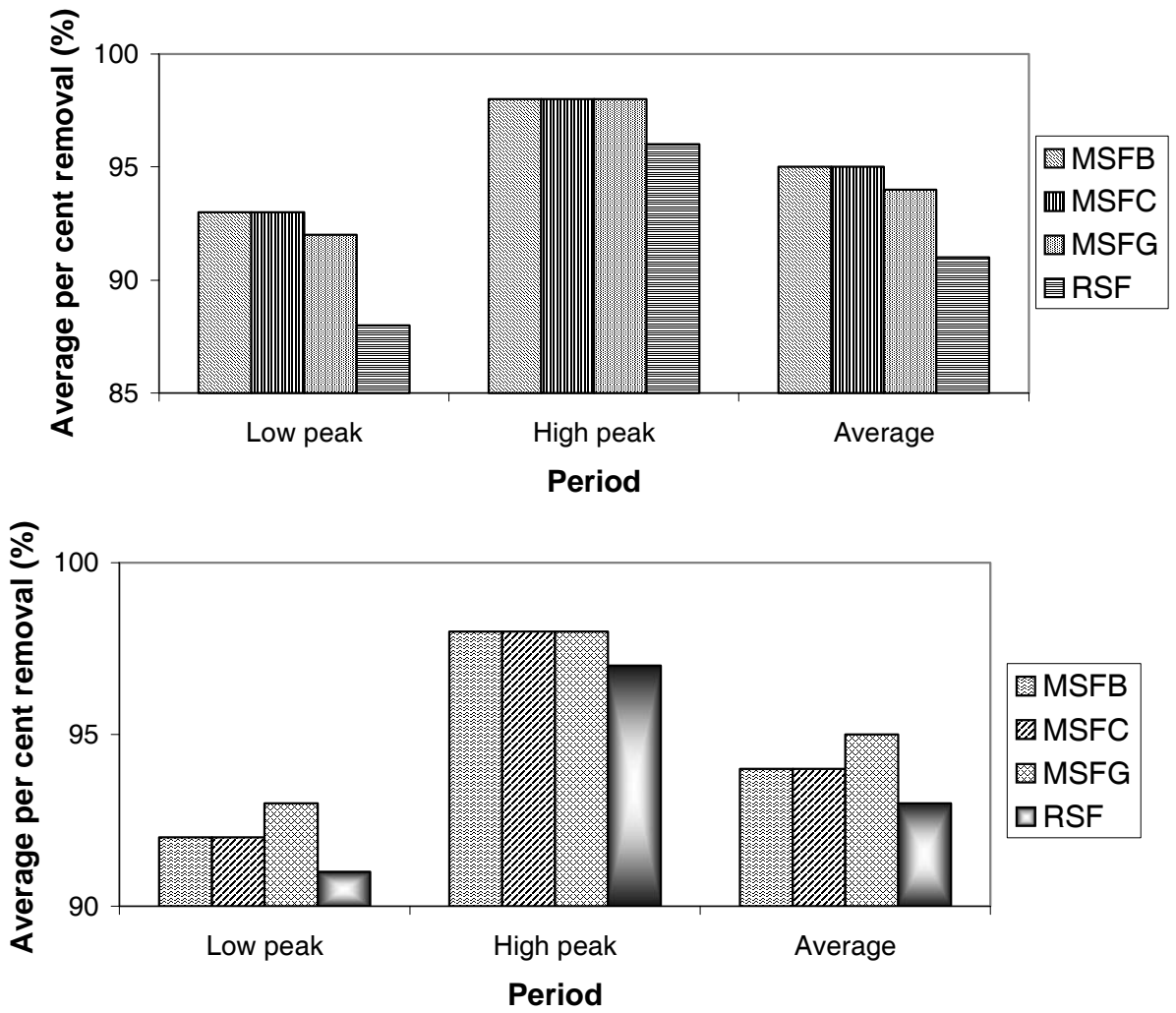


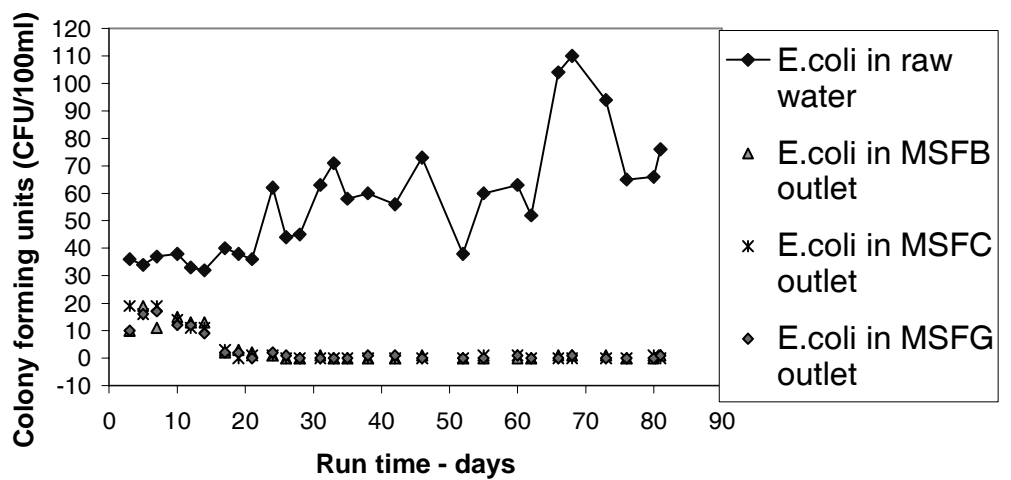

Figure 8

Comparison of E.coli levels in raw water and MSFs outlet

Figure 9

Comparison of total coli levels in raw water and MSFs outlet

$\triangle$ Total coli in MSFC outlet

- Total coli in MSFG outlet

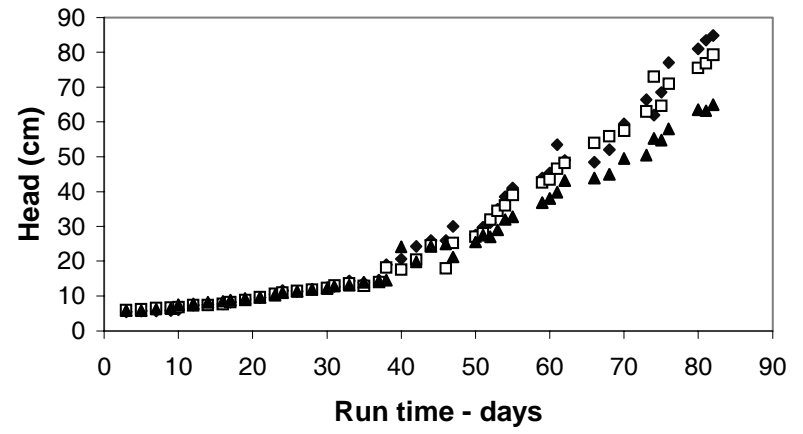

TABLE 5

Average and ranges of the MSF and RSF effluents' selected quality parameter levels vs. the KEBS drinking water standards

\begin{tabular}{|c|c|c|c|c|c|}
\hline & Parameter & $\begin{array}{c}\text { Avg. SS } \\
(\mathrm{mg} / \mathrm{l})\end{array}$ & $\begin{array}{l}\text { Avg. } \\
\text { turbidity } \\
\text { (NTU) }\end{array}$ & $\begin{array}{l}\text { E. coli- } \\
\text { CFU/100 me } \\
\text { (range) }\end{array}$ & $\begin{array}{l}\text { Total coli - } \\
\text { CFU/100 me } \\
\text { (range) }\end{array}$ \\
\hline 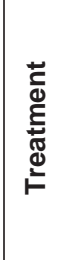 & $\begin{array}{l}\text { MSFB } \\
\text { MSFC } \\
\text { MSFG } \\
\text { RSF } \\
\text { KEBS }^{1}\end{array}$ & $\begin{array}{c}0.85 \\
0.83 \\
0.91 \\
1.76 \\
\mathrm{Nil}\end{array}$ & $\begin{array}{c}1.03 \\
0.99 \\
1.04 \\
1.5 \\
5 \text { but }<1 \text { for } \\
\text { effective } \\
\text { disinfection }\end{array}$ & $\begin{array}{c}0-1 \\
0-1 \\
0-1 \\
8-46 \\
\text { Shall be } \\
\text { absent }\end{array}$ & $\begin{array}{c}2-8 \\
1-13 \\
0-11 \\
26-110 \\
\text { Shall be } \\
\text { absent }\end{array}$ \\
\hline
\end{tabular}

(Source: Field test data: 2000; GoK, 1996)

${ }^{1}$ KEBS recommendation
- Head loss in SSFB

$\square$ Head loss in SSFC

$\Delta$ Head loss in SSFG
Figure 10

Observed head loss development in the SSF units of the MSFS recorded the least range of 0 to $1 \mathrm{CFU} / 100 \mathrm{~m} \ell$ and 1 to $13 \mathrm{CFU} / 100 \mathrm{~m} \ell$ with respect to $E$. coli and total coliforms respectively. Given that the final RSF filtrate has to be disinfected, in trying to compare the quantity and extent of disinfection required for both systems in this case, it would suffice to say that it would cost more to disinfect the RSF filtrate than the MSF filtrates when considering the levels of bacteriological concentrations in both systems' outlet.

\section{Head loss (resistance) development in SSFs}

Figure 10 shows the field-observed trends in filter bed resistance development in the three SSFs.

As expected, head loss increased gradually and steadily during the first 28 to $30 \mathrm{~d}$ (maturation period) in all the SSFs. At this stage, the filtration rates were set constant and same for all the SSFs $(0.29 \mathrm{~m} / \mathrm{h})$. After maturation, filtration rates were set constant but different in each SSF (SSFB at $0.29 \mathrm{~m} / \mathrm{h}, \mathrm{SSFC}$ at $0.23 \mathrm{~m} / \mathrm{h}$, and SSFG at $0.18 \mathrm{~m} / \mathrm{h}$ ). Head loss trends exhibited a sharp increase with time after maturation. The trend increased in relation to the filtration rate. After $82 \mathrm{~d}$ of operation, none of the SSFs had reached the maximum recommended head loss of $1 \mathrm{~m}$. This was attributed to the fact that the HRF effluent turbidity and SS levels were within the required range for optimal SSF operation (5 to $10 \mathrm{NTU}$ ). 


\section{Conclusions}

It was shown that the MSFs performed better than the conventional system in general removal efficiency with regard to the parameters put to the test. With special reference to the bacteriological quality improvement, the MSF system greatly improved the bacteriological quality of the water. In this regard, MSFs recorded removal efficiencies of over $99 \%$ and $98 \%$ respectively for E. coli and total coliforms. Despite the observed performance, MSF should be complemented with chlorination as a final buffer against waterborne diseases. However, in this case, the dosing would be greatly reduced. In terms of the filter run periods, the MSFs at Moi University can run for more than the recorded 12 weeks before clogging the SSF units to warrant cleaning when operated at the pilot-plant conditions. This was also an indicator of the performance of the chosen HRF material as suitable filter material as well as field operating conditions having been set within the required specifications. In general, none of the systems conclusively met the set KEBS drinking water standards. However, MSF final effluent quality was closest to the set standards compared to those of conventional systems indicating the viability of such systems for adequate treatment of drinking water. We can therefore conclude that with proper design specifications, MSFs perform better than conventional systems under similar conditions of raw water quality and environmental conditions. The locally available material, i.e. broken burnt bricks and improved agricultural waste (charcoal maize cobs), can also be effectively used as pretreatment media and therefore could serve as alternatives where natural gravel is not readily available.

\section{Acknowledgements}

The authors would like to thank Moi University and the Netherlands Government through the MHO - WRE Project for offering the principal author the scholarship and project funds that enabled this study to be undertaken.

\section{References}

BOLLER M (1993) Filter mechanisms in roughing filters. J. Water Supply Res. and Technol. - AQUA Vol. 42 174-185.

DESHPANDE CV and HINGORANI HK (1997) Rejuvenation of slow sand filtration using horizontal roughing flow filtration technique. In: Proc. $23^{\text {rd }}$ WEDC Conference. Water and Sanitation for All: Partnerships and Innovations. India, 227-279.

GALVIS G, VISSCHER JT, FERNA'NDEZ J and BERO'N F (1993) Pretreatment alternatives for drinking water supply systems: Selection, design, operation and maintenance. Occasional Paper 22. IRC, The Hague, The Netherlands.

KENYA BUREAU OF STANDARDS (KEBS) (1996) Kenya Standard Specification for Drinking Water. Part 1. The Requirements for Drinking Water and Containerized Drinking Water (First Revision, 1996). Kenya Bureau of Standards, Government of Kenya (GoK), Kenya.

PESCOD MB, ABOUZAID H and SUNDARESAN BB (1990) Slow Sand Filtration: A Low Cost Treatment for Water Supplies in Developing Countries. Water Research Centre (WRc), UK.

TEBBUTT THY (1992) Principles of Water Quality Control (4 ${ }^{\text {th }}$ edn.). Pergamon Press, Oxford.

VISSCHER JT, PARAMASIVAN R and HEIJNEN HA (1997) Slow sand filtration: Planning, design, construction, operation and maintenance. Technical Paper No. 24. IRC. The Hague, The Netherlands.

WEGELIN M (1996) Surface Water Treatment by Roughing Filters. A Design, Construction and Operation Manual. SANDEC Report No. 2/96. Swiss Centre for Development Cooperation in Technology and Management (SKAT), CH - 9000 St. Gallen, Switzerland.

WEGELIN M, SCHERTENLEIB R and BOLLER M (1990) The decade of roughing filters: The development of rural water-treatment process for developing countries. J. Water SRT - AQUA 14 (5) 304-316.

WEGELIN M (1986) Horizontal Flow Roughing Filtration (HRF): A Design, Construction, and Operation Manual. IRCWD Report No. $06 / 86$.

WHO and UNICEF (1996) Water Supply and Sanitation Sector Monitoring Report: Sector Status as of $31^{\text {st }}$ December 1994. World Health Organization, Geneva, Switzerland. 
